\title{
Mate selection allows changing the genetic variability of the progeny while optimizing genetic response and controlling inbreeding
}

\author{
Grazyella Massako Yoshida ${ }^{\mathrm{a}, \mathrm{b}}$, José Manuel Yáñez ${ }^{\mathrm{b}, \mathrm{c}, \mathrm{d}}$, Carlos Antonio Lopes de Oliveira ${ }^{\mathrm{e}}$, \\ Ricardo Pereira Ribeiro $^{\mathrm{e}}$, Jean Paul Lhorente ${ }^{\mathrm{d}}$, Sandra Aidar de Queiroz ${ }^{\mathrm{a}}$, Roberto Carvalheiro ${ }^{\mathrm{a}, *}$ \\ a Animal Science Department, Universidade Estadual Paulista "Júlio de Mesquita Filho" (UNESP), Campus Jaboticabal, Faculdade de Ciências Agrárias e Veterinárias \\ (FCAV), Via de Acesso Prof. Paulo Donato Castellane, 14884-900 Jaboticabal, Brazil \\ ${ }^{\mathrm{b}}$ Facultad de Ciencias Veterinarias y Pecuarias, Universidad de Chile, Av Santa Rosa 11735, La Pintana, Santiago 8820808, Chile \\ ${ }^{\mathrm{c}}$ Núcleo Milenio de Salmónidos Invasores, Concepción, Chile \\ d Aquainnovo, Cardonal s/n, Lote B, $2^{\circ}$ Piso Planta Proceso, Puerto Montt, Chile \\ e Animal Science Department, Universidade Estadual de Maringá, Av Colombo 5790, 87020-900 Maringá, Brazil
}

\section{A R T I C L E I N F O}

\section{Keywords:}

Breeding program

Coancestry

Inbreeding

Genetic gain

Oncorhynchus kisutch

Oreochromis niloticus

\begin{abstract}
A B S T R A C T
This study aims to compare results obtained by mate selection accounting for different components in the objective function (OF), including functions related to genetic variability of the future progeny, using Nile tilapia and coho salmon real datasets. A total of 8782 Nile tilapias (NP) from five generations and 79,144 coho salmon (CS) from eight generations were used to optimize different OF accounting for coancestry of parents, expected genetic merit, inbreeding and components associated to genetic variability of the progeny. The candidates for selection were the superior animals of the last generation, corresponding to 281 males for NP population and 328 males for CS population, to be mated with 179 and 440 superior females, respectively. Candidate males were allowed to be mated with a maximum of four females. Different functions related to genetic variability of the progeny were tested in the mate selection and we observed that it was possible to increase the genetic variability or produce more uniform progeny, for both species studied. In addition, some OFs also allowed increasing the number of outstanding superior progeny. The tested OF were effective in optimizing the genetic gain and keeping the coancestry and inbreeding at controlled rates, while reducing or increasing the genetic variability of progeny, depending on the purpose of production.
\end{abstract}

\section{Introduction}

Maintenance of genetic variation within a breeding program is essential for long-term sustainable genetic improvement of fish (Kause et al. 2014). However, selection of breeders from a small number of families and high selection intensity could reduce the genetic variability of the population, increase rates of inbreeding and reduce the genetic progress (Gjedrem, 2005). In contrast, the maintenance of genetic variability required in a breeding nucleus contradicts the practical aims of commercial producers. In tilapia production, for instance, commercial farmers are usually awarded for selling fish within the preferred weight range determined by the market (Khaw et al. 2016). Growth uniformity is preferable at commercial level since it allows to deliver more uniform product, harvest a larger proportion of the population at market size, and reduce the need of size grading and multiple harvests (Gilmour et al. 2005; Janhunen et al. 2012a, 2012b). Furthermore, more uniform growth may also reduce competitive interactions between animals, which contributes to reduce feed monopolization and dominant behavior, and thus improve well-being of fish (Baras and Jobling 2002).

The increasing demand from consumers and commercial farmers for uniformity of production is one of the driving forces for animal breeders to emphasize more this criterion in the selection process (Sae-Lim et al. 2012). Some studies quantified the genetic variation for uniformity in fish and concluded that it is possible to increase uniformity of production by selective breeding in Nile tilapia (Khaw et al. 2016; Marjanovic et al. 2016; Moreno et al. 2012; Omasaki et al. 2017) and in salmonids (Jakobsen et al. 1987; Sae-Lim et al. 2017, 2015, 2012). In addition, different strategies can be used to reduce variability in aquaculture species, such as the use of mono-sex fish (Beardmore et al. 2001), grading the fishes at several stages during the grow-out phase (King et al. 2006) and performing planned mating (Hohenboken 1985).

Genetic variability of progeny could also be accounted for by mate selection (Piyasatian and Kinghorn 2003). When mate selection is used,

\footnotetext{
* Correspondence author.

E-mail address: roberto.carvalheiro@unesp.br (R. Carvalheiro).
} 
the selection and mate allocation decisions are performed simultaneously by the optimization of an objective function (OF) considering different components (Shepherd and Kinghorn 1999; Kinghorn 2011). Based on optimum contribution selection (OCS) theory, the elementary components to be included in the OF are the expected genetic merit of the progeny and the coancestry among selected parents (Meuwissen 1997; Woolliams and Thompson 1994). The optimization of the OF accounting for these two components allows a higher long-term genetic response than truncation selection, under the same rate of inbreeding (Sonesson and Meuwissen 2000; Woolliams et al. 2015).

Components related to genetic variability could also be accommodated in the OF (Piyasatian and Kinghorn 2003), aiming to increase or reduce the genetic variability of the future progeny according to the interest. This is of great importance to both selection nuclei and multipliers due to the arguments described previously. The supposed benefit of using this strategy, under a mate selection approach, is that the relevant components to be considered in a breeding program could be optimized simultaneously, decreasing the chance of finding a suboptimal solution by performing selection and mating decisions independently. It is unclear, however, in which extend accounting for genetic variability of the progeny would affect the other components to be optimized such as genetic gain and coancestry.

In the present study, we compared the results of mate selection using different $\mathrm{OF}$ in real Nile tilapia and coho salmon datasets, aiming to investigate if mate selection would allow shaping the genetic variability of the future progeny while optimizing genetic response and controlling inbreeding or, more specifically, to contrast the results of different OF accounting (explicitly) or not for the genetic variability of the progeny.

\section{Material and methods}

\subsection{Nile tilapia dataset}

The dataset used in this study contained pedigree information and standardized estimated breeding values (sEBV) for harvest weight of 8782 Nile tilapias from five generations (Table 1), provided by PeixeGen Research Group (Universidade Estadual de Maringá, Maringá, PR, Brazil).

The animals evaluated in each generation were produced using natural mating and were obtained from a mate design using two females per male. Inspection of the presence of spawning was done two times per week in the breeding season (from November to February). When the spawning was identified, the sire was removed from the hapa and the dam and the larvae were kept together until the end of breeding season. After that, 100 fingerlings from each family were divided into two equal groups and transferred for nursery structure until the average weight of about $10 \mathrm{~g}$, when 50 animals per family, randomly chosen, were individually identified by passive integrated transponder (PIT) tags, implanted in the visceral cavity. After the identification, the animals were transferred to the grow-out system in cages where they were weighted with approximately 7 months of age.

More details about the origin, family and reproduction structure of the Nile tilapia population were described by Oliveira et al. (2016) and Yoshida et al. (2017).

\subsection{Coho salmon dataset}

The coho salmon dataset used in this study contained pedigree information and standardized economic index (sIndex) of 79,144 coho salmon from the even population of AquaChile Breeding Program based at Puerto Montt, Chile, comprising eight generations (Table 2). The sIndex included breeding values for weight at harvest and resistance to P. salmonis.

The spawning was induced using hormone and all families were generated within one or two weeks using three to five females per male as mate design. The eggs of each full-sib family were incubated separately, and at eyed stage 2000 eggs of each selected family were moved to individual tanks ( 4001 each) until they weighted about 5 to $7 \mathrm{~g}$ when the animals were identified individually using PIT (Passive Integrated Transponder) tags. Then, 60 to 80 animals per family were transferred into two to three smoltification cages in fresh water conditions. Smoltification occurred naturally at eight months post-spawning and the weight at harvest time $(\sim 3 \mathrm{~kg})$ was recorded at $20-21$ months of age. More details about this population can be seen at Dufflocq et al. (2016) and Yañez et al. (2014, 2016).

\subsection{Objective function}

The basic mate selection OF (OF1), used as the standard for comparison with the remaining tested OFs (OF2-OF7), was defined as:

$\mathrm{OF} 1=\mathrm{w}_{1} \mathrm{x}^{\prime} \mathrm{EBV}+\mathrm{w}_{2} \mathrm{x}^{\prime} \mathrm{Ax}+\mathrm{w}_{3} \overline{\mathrm{F}}$

where, $x^{\prime} \mathrm{EBV}$ is the expected merit of the future progeny; $\mathrm{x}^{\prime} \mathrm{Ax}$ is the weighted mean coancestry of selected parents; $\overline{\mathrm{F}}$ is the expected average inbreeding coefficient of the future progeny; $w_{1}$ to $w_{3}$ are the corresponding weighting factors and $\mathrm{x}$ is the vector to be optimized of genetic contributions for each candidate (the symbol' denotes a transposed vector). The weights $\mathrm{w}_{1}$ to $\mathrm{w}_{3}$ were defined in previous studies, based on their compromise in finding a good balance between genetic response and control of inbreeding, for the Nile tilapia (Yoshida et al. 2017: $\mathrm{w}_{1}=1, \mathrm{w}_{2}=-20$ and $\mathrm{w}_{3}=-1$ ) and coho salmon population (Yoshida et al. 2016: $\mathrm{w}_{1}=1, \mathrm{w}_{2}=-100$ and $\mathrm{w}_{3}=-1$ ). This $\mathrm{OF}$ is expected to provide the same long-term genetic response and rate of inbreeding as OCS combined with minimum inbreeding mating (Yoshida et al. 2018).

Six alternative OFs (OF2-OF7) were tested including, in addition to the components of OF1, at least one of the following (empirically determined) components related to the genetic variability of the progeny:

Ntop: number of animals in the future progeny with expected genetic merit (mean of parents' EBVs) greater than a certain threshold (3 genetic standard deviations for Nile tilapia and 3.5 for coho salmon), aiming at producing a greater proportion of outstanding (superior) animals;

vEBVt: mean value of sEBV (sIndex) to the cube of future progeny of dams classified as top $50 \%$, favoring the occurrence of positive

Table 1

General information, inbreeding coefficient and standardized estimated breeding value for harvest weight of Nile tilapia, per generation.

\begin{tabular}{|c|c|c|c|c|c|c|c|c|}
\hline \multirow[t]{2}{*}{ Gen } & \multicolumn{4}{|c|}{ Number } & \multicolumn{3}{|c|}{ Inbreeding } & \multirow[t]{2}{*}{$s E B V \pm S D$} \\
\hline & Sires & Dams & Families & Progeny & Mean & Min. & Max. & \\
\hline 1 & 24 & 33 & 33 & 1731 & 0 & 0 & 0 & $-0.01 \pm 1.11$ \\
\hline 2 & 40 & 57 & 58 & 1717 & 0 & 0 & 0 & $0.07 \pm 0.55$ \\
\hline 3 & 52 & 79 & 79 & 2695 & 0 & 0 & 0 & $0.39 \pm 0.71$ \\
\hline 4 & 39 & 44 & 50 & 1127 & 0.00319 & 0 & 0.06300 & $0.83 \pm 1.01$ \\
\hline 5 & 29 & 42 & 51 & 1455 & 0.00016 & 0 & 0.00800 & $0.97 \pm 1.28$ \\
\hline
\end{tabular}

sEBV, standardized estimated breeding value; SD, standard deviation; Gen, generation; Min, minimum; Max, Maximum; sEBV = EBV/83.036. 
Table 2

General information, inbreeding coefficient and standardized economic index for coho salmon, per generation.

\begin{tabular}{|c|c|c|c|c|c|c|c|c|}
\hline \multirow[t]{2}{*}{ Gen } & \multicolumn{4}{|c|}{ Number } & \multicolumn{3}{|c|}{ Inbreeding } & \multirow[t]{2}{*}{ sIndex \pm SD } \\
\hline & Sires & Dams & Families & Progeny & Mean & Min & Max & \\
\hline 1998 & 42 & 81 & 81 & 8619 & 0.000 & 0.000 & 0.000 & $-0.05 \pm 0.23$ \\
\hline 2000 & 36 & 73 & 73 & 6557 & 0.002 & 0.000 & 0.125 & $0.37 \pm 0.30$ \\
\hline 2002 & 59 & 114 & 114 & 9120 & 0.025 & 0.000 & 0.125 & $0.63 \pm 0.38$ \\
\hline 2004 & 49 & 137 & 137 & 10,761 & 0.047 & 0.000 & 0.172 & $1.32 \pm 0.31$ \\
\hline 2006 & 37 & 102 & 102 & 10,523 & 0.062 & 0.016 & 0.203 & $1.65 \pm 0.37$ \\
\hline 2008 & 34 & 98 & 98 & 8821 & 0.063 & 0.027 & 0.191 & $1.97 \pm 0.33$ \\
\hline 2010 & 45 & 110 & 110 & 8798 & 0.070 & 0.035 & 0.126 & $2.37 \pm 0.28$ \\
\hline 2012 & 61 & 112 & 112 & 15,945 & 0.081 & 0.056 & 0.162 & $2.74 \pm 0.36$ \\
\hline
\end{tabular}

sIndex, standardized economic index; SD, standard deviation; Gen, generation; Min, minimum; Max, Maximum; sIndex = Index/6.79329.

associative mating for the superior dams, also aiming at producing a greater proportion of outstanding (superior) animals;

vEBVb: mean value of sEBV (sIndex) to the cube of future progeny of dams classified as bottom $50 \%$, favoring the occurrence of negative associative mating for the inferior dams, to avoid the production of progeny with extreme lower sEBV (sIndex).

The alternative OFs which included all the components (OF6 and OF7) were specified as:

OF6 (7) $=\mathrm{w}_{1} \mathrm{x}^{\prime} \mathrm{EBV}+\mathrm{w}_{2} \mathrm{x}^{\prime} \mathrm{Ax}+\mathrm{w}_{3} \overline{\mathrm{F}}+\mathrm{w}_{4} \mathrm{Ntop}+\mathrm{w}_{5} \mathrm{vEBVt}+\mathrm{w}_{6} \mathrm{vEBVb}$

where, $\mathrm{w}_{4}$ to $\mathrm{w}_{6}$ correspond to the weights given to the respective components related to progeny variability and the other components are as previously described. The other alternative strategies included only Ntop (OF2), Ntop and vEBVb (OF3), vEBVt (OF4) and vEBVb (OF5). The weights used for the different components of each OF for Nile tilapia and coho salmon are presented in Tables 3 and 4, respectively.

The components $\bar{F}$,Ntop, vEBVt and vEBVb, when included in the $\mathrm{OF}$, determined the mate allocations indirectly following the problem representation proposed by (Gondro and Kinghorn 2008), which uses an auxiliary vector of real numbers representing the "rankings" (order) of mates to be performed (Gondro and Kinghorn 2008; Shepherd and Kinghorn 1998). This auxiliary vector of real numbers was optimized together with $\mathrm{x}$ vector. The objective functions were optimized using a differential evolution algorithm developed in FORTRAN language (Carvalheiro et al. 2010a, 2010b).

For Nile tilapia, the best four females (179 animals) and six males (281 animals) per family of the fifth generation were considered as selection and mate candidates, excluding the animals with negative EBV. For coho salmon, the top three males (328) and four females (440) with positive economic index from 112 families of the class-year 2012 were considered as selection and mate candidates. The preselection of candidates, choosing just the top animals within families, was made to decrease the dimensionality/complexity of the optimization problem and, consequently, attain a faster optimization of the OF. This, however, is not expected to change the final result as animals with negative EBVs would hardly be selected by the optimization algorithm. For both species, each candidate female was mated once (i.e. female contribution was not optimized) and the males were allowed to be mated with a maximum of four females.

\section{Results}

\subsection{Nile tilapia}

The optimization of the objective functions for mate selection, considering components related to genetic variability of the future progeny (OF2 to OF7), indicated that the applied algorithm allowed to change the standard deviation (SD) of expected sEBVs of the future progeny, while keeping genetic merit, coancestry and inbreeding at similar levels to those of OF1 (Table 3).

The lowest and highest SD were observed, respectively, by the optimization of the objective function that favored the occurrence of corrective (OF5, $\mathrm{SD}=0.246)$ and positive associative (OF4, $\mathrm{SD}=0.771)$ mating, corresponding to $51.6 \%(\mathrm{OF} 5)$ and $161.6 \%(\mathrm{OF} 4)$ of the SD presented by OF1. These mates (OF5 and OF4) presented the lowest $(0.3 \%)$ and highest $(2.4 \%)$ average inbreeding value of the future progeny, respectively (Table 3). OF1 presented an average inbreeding of $0.5 \%$.

The optimization of OFs considering Ntop was effective in increasing the expected number of outstanding (superior) progeny in comparison with OFs not using Ntop. The greatest Ntop value was

Table 3

Weights $\left(\mathrm{w}_{1}-\mathrm{w}_{6}\right)$ applied to the different objective functions (OF1-7), respective optimized results for the expected genetic merit of the future progeny ( $\left.\mathrm{x}^{\prime} \mathrm{EBV}\right)$ and its standard deviation (SD), coancestry ( $\left.x^{\prime} \mathrm{Ax}\right)$, inbreeding of the future progeny $(\overline{\mathrm{F}})$, expected number of outstanding progeny (Ntop) and number of sires selected (nSire), for mate selection in Nile tilapia.

\begin{tabular}{|c|c|c|c|c|c|c|c|c|c|c|c|c|}
\hline $\mathrm{OF}$ & $\mathrm{w}_{1}$ & $\mathrm{w}_{2}$ & $\mathrm{w}_{3}$ & $\mathrm{w}_{4}$ & $\mathrm{w}_{5}$ & $\mathrm{w}_{6}$ & $\mathrm{x}^{\prime} \mathrm{EBV}$ & SD & $\mathrm{x}^{\prime} \mathrm{Ax}$ & $\overline{\mathrm{F}}$ & Ntop & nSire \\
\hline 1 & 1 & -20 & -1 & 0 & 0 & 0 & 2.434 & 0.477 & 0.025 & 0.005 & 23 & 72 \\
\hline 2 & 1 & -20 & -1 & 1 & 0 & 0 & $\begin{array}{l}2.432 \\
(99.9)^{\mathrm{a}}\end{array}$ & $\begin{array}{l}0.601 \\
(126.0)\end{array}$ & $\begin{array}{l}0.026 \\
(104.0)\end{array}$ & $\begin{array}{l}0.012 \\
(240.0)\end{array}$ & $\begin{array}{l}64 \\
(278.3)\end{array}$ & $\begin{array}{l}74 \\
(102.8)\end{array}$ \\
\hline 3 & 1 & -20 & -1 & 1 & 0 & 1 & $\begin{array}{l}2.473 \\
(101.6)\end{array}$ & $\begin{array}{l}0.497 \\
(104.2)\end{array}$ & $\begin{array}{l}0.028 \\
(112.0)\end{array}$ & $\begin{array}{l}0.009 \\
(180.0)\end{array}$ & $\begin{array}{l}64 \\
(278.3)\end{array}$ & $\begin{array}{l}68 \\
(94.4)\end{array}$ \\
\hline 4 & 1 & -20 & -1 & 0 & 1 & 0 & $\begin{array}{l}2.357 \\
(96.8)\end{array}$ & $\begin{array}{l}0.771 \\
(161.6)\end{array}$ & $\begin{array}{l}0.029 \\
(116.0)\end{array}$ & $\begin{array}{l}0.024 \\
(480.0)\end{array}$ & $\begin{array}{l}34 \\
(147.8)\end{array}$ & $\begin{array}{l}94 \\
(130.6)\end{array}$ \\
\hline 5 & 1 & -20 & -1 & 0 & 0 & 1 & $\begin{array}{l}2.455 \\
(100.9)\end{array}$ & $\begin{array}{l}0.246 \\
(51.6)\end{array}$ & $\begin{array}{l}0.027 \\
(108.0)\end{array}$ & $\begin{array}{l}0.003 \\
(60.0)\end{array}$ & $\begin{array}{l}7 \\
(30.4)\end{array}$ & $\begin{array}{l}70 \\
(97.2)\end{array}$ \\
\hline 6 & 1 & -20 & -1 & 0.01 & 0.01 & 0.01 & $\begin{array}{l}2.446 \\
(100.5)\end{array}$ & $\begin{array}{l}0.653 \\
(136.9)\end{array}$ & $\begin{array}{l}0.026 \\
(104.0)\end{array}$ & $\begin{array}{l}0.007 \\
(140.0)\end{array}$ & $\begin{array}{l}35 \\
(152.2)\end{array}$ & $\begin{array}{l}70 \\
(97.2)\end{array}$ \\
\hline 7 & 1 & -20 & -1 & 1 & 1 & 1 & $\begin{array}{l}2.458 \\
(101.0)\end{array}$ & $\begin{array}{l}0.642 \\
(134.6)\end{array}$ & $\begin{array}{l}0.030 \\
(120.0)\end{array}$ & $\begin{array}{l}0.011 \\
(220.0)\end{array}$ & $\begin{array}{l}36 \\
(156.5)\end{array}$ & $\begin{array}{l}70 \\
(97.2)\end{array}$ \\
\hline
\end{tabular}

\footnotetext{
${ }^{\mathrm{a}}$ Numbers between brackets refer to the percentage of each value in comparison with the corresponding value presented by OF1.
} 
Table 4

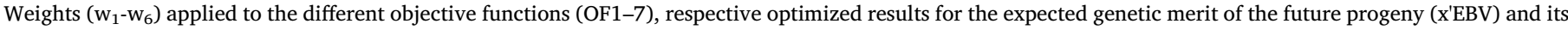

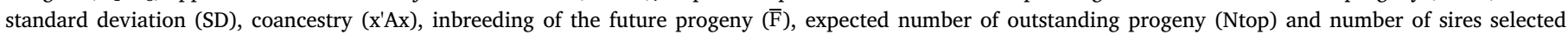
(nSire), for mate selection in coho salmon.

\begin{tabular}{|c|c|c|c|c|c|c|c|c|c|c|c|c|}
\hline $\mathrm{OF}^{*}$ & $\mathrm{w}_{1}$ & $\mathrm{w}_{2}$ & $w_{3}$ & $\mathrm{w}_{4}$ & $w_{5}$ & $\mathrm{w}_{6}$ & $x^{\prime} E B V$ & SD & $x^{\prime} A x$ & $\overline{\mathrm{F}}$ & Ntop & nSire \\
\hline 1 & 1 & -100 & -1 & 0 & 0 & 0 & 3.163 & 0.232 & 0.151 & 0.079 & 22 & 145 \\
\hline 2 & 1 & -100 & -1 & 1 & 0 & 0 & $\begin{array}{l}3.174 \\
(100.3)^{\mathrm{a}}\end{array}$ & $\begin{array}{l}0.293 \\
(126.3)\end{array}$ & $\begin{array}{l}0.151 \\
(100.0)\end{array}$ & $\begin{array}{l}0.091 \\
(115.2)\end{array}$ & $\begin{array}{l}118 \\
(536.4)\end{array}$ & $\begin{array}{l}142 \\
(97.9)\end{array}$ \\
\hline 3 & 1 & -100 & -1 & 1 & 0 & 1 & $\begin{array}{l}3.183 \\
(100.6)\end{array}$ & $\begin{array}{l}0.265 \\
(114.2)\end{array}$ & $\begin{array}{l}0.151 \\
(100.0)\end{array}$ & $\begin{array}{l}0.085 \\
(107.6)\end{array}$ & $\begin{array}{l}117 \\
(531.8)\end{array}$ & $\begin{array}{l}139 \\
(95.9)\end{array}$ \\
\hline 4 & 1 & -100 & -1 & 0 & 1 & 0 & $\begin{array}{l}3.233 \\
(102.2)\end{array}$ & $\begin{array}{l}0.279 \\
(120.3)\end{array}$ & $\begin{array}{l}0.155 \\
(102.6)\end{array}$ & $\begin{array}{l}0.087 \\
(110.1)\end{array}$ & $\begin{array}{l}75 \\
(340.9)\end{array}$ & $\begin{array}{l}184 \\
(126.9)\end{array}$ \\
\hline 5 & 1 & -100 & -1 & 0 & 0 & 1 & $\begin{array}{l}3.167 \\
(100.1)\end{array}$ & $\begin{array}{l}0.145 \\
(62.5)\end{array}$ & $\begin{array}{l}0.151 \\
(100.0)\end{array}$ & $\begin{array}{l}0.079 \\
(100.0)\end{array}$ & $\begin{array}{l}10 \\
(45.5)\end{array}$ & $\begin{array}{l}145 \\
(100.0)\end{array}$ \\
\hline 6 & 1 & -100 & -1 & 0.01 & 0.01 & 0.01 & $\begin{array}{l}3.169 \\
(100.2)\end{array}$ & $\begin{array}{l}0.299 \\
(128.9)\end{array}$ & $\begin{array}{l}0.151 \\
(100.0)\end{array}$ & $\begin{array}{l}0.081 \\
(102.5)\end{array}$ & $\begin{array}{l}64 \\
(290.9)\end{array}$ & $\begin{array}{l}143 \\
(98.6)\end{array}$ \\
\hline 7 & 1 & -100 & -1 & 1 & 1 & 1 & $\begin{array}{l}3.235 \\
(102.3)\end{array}$ & $\begin{array}{l}0.275 \\
(118.5)\end{array}$ & $\begin{array}{l}0.155 \\
(102.6)\end{array}$ & $\begin{array}{l}0.089 \\
(112.7)\end{array}$ & $\begin{array}{l}82 \\
(372.7)\end{array}$ & $\begin{array}{l}174 \\
(120.0)\end{array}$ \\
\hline
\end{tabular}

a Numbers between brackets refer to the percentage of each value in comparison with the corresponding value presented by OF1.

observed by OF2 and OF3, being almost three fold higher than the Ntop from OF1. OF5 presented the lowest Ntop, corresponding to $30.5 \%$ of the Ntop presented by OF1, as a result of favoring the occurrence of corrective mating. Except for OF4, the number of sires selected was similar among the OFs (Table 3).

The distributions of the expected genetic values of the future progeny (Fig. 1) reinforce the results presented in Table 3. In comparison with OF1, a greater dispersion of sEBVs was observed for OF4, where there is a higher proportion of animals with upper and lower extreme sEBVs, resultant from the associative positive mating favored by considering vEBVt in the OF to be optimized. OF5 presented a higher proportion of progeny with expected genetic merit around the mean, as the component $\mathrm{vEBVb}$ favored the occurrence of corrective mating. In addition, it is possible to observe that OF2 and OF3 were effective in increasing the expected proportion of progeny with $\mathrm{SEBV}$ above three genetic standard deviations (Fig. 1A). When considering simultaneously the three components related to progeny variability (OF6 and OF7), there was an increase in the frequency of animals with extreme upper and also lower sEBVs compared to OF1 (Fig. 1B). However, the increase in extreme lower sEBVs of OF6 and OF7 was not as pronounced as that presented by OF4, which did not consider vEBVb.

\subsection{Coho salmon}

The coho salmon population reinforced the result that considering the genetic variability of the future progeny on mate selection (OF2 to OF7) allows changing the dispersion of the expected genetic merit of the future progeny without compromising genetic gain, coancestry and inbreeding, in comparison to OF1 (Table 4).

OF2 and OF3 were very effective in increasing the expected number of outstanding animals, providing a 5 fold increase on Ntop compared to OF1 (Table 4). OF4, which favored positive assortative mating, also allowed increasing the expected proportion of outstanding progeny but, differently from Nile tilapia, presented similar distribution for lower sEBVs than OF1 (Fig. 2). It is important to note that the expected genetic merit of the future progeny for OF4 was slightly lower (96.8\%) than OF1 for Nile tilapia (Table 3), the opposite occurring (102.2\%) for coho salmon (Table 4).

Similarly as in Nile tilapia, OF5 presented a lower dispersion of the expected genetic merit of the future progeny compared to the other OFs in the coho salmon population. The OFs which considered simultaneously all the components related to progeny variability (OF6 and OF7) also presented in coho salmon a good compromise in increasing the expected proportion of outstanding progeny while keeping the other components similar to those of OF1 (Table 4 and Fig. 2).

\subsection{Discussion}

The use of components related to genetic variability of the progeny in the objective function allowed changing the dispersion of their expected breeding values by directing the mating according to the proposed objective. In Nile tilapia, the different OFs varied more regarding the dispersion of expected EBVs compared to coho salmon population. This occurred probably because the coho salmon population is more inbred than the Nile tilapia population. Thus, the algorithm had a smaller parametric space to explore the genetic variability of the progeny while keeping inbreeding controlled.

It should be noted that there is no general rule for choosing the weights of each component of the OF. The definition of the best values for the weights related to progeny variability depends on the purpose to use the animals, in breeding nucleus or as multipliers. An alternative to be further investigated would be to modify the algorithm to also optimize the weights. This, however, would probably characterize a multiobjective optimization problem with conflicting objectives, without a
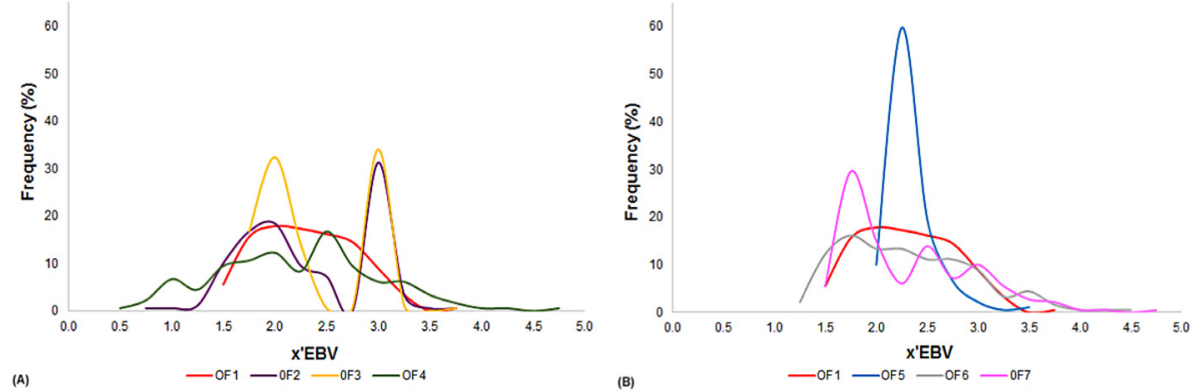

Fig. 1. Distribution of expected genetic merit of the future progeny according to different objective functions (OF) for mate selection accounting (OF2 to OF7) or not (OF1) for the genetic variability of the future progeny, in Nile tilapia. 

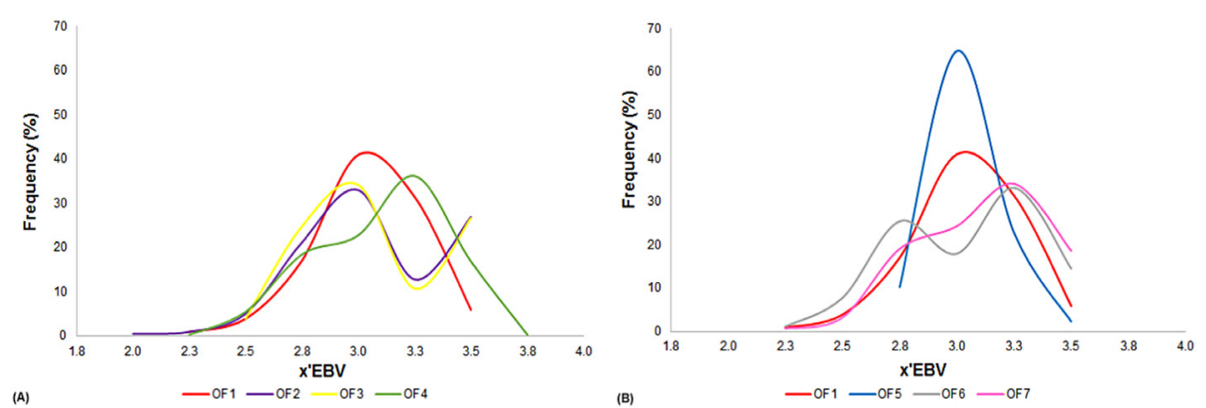

Fig. 2. Distribution of expected genetic merit of the future progeny according to different objective functions (OF) for mate selection accounting (OF2 to OF7) or not (OF1) for the genetic variability of the future progeny, in coho salmon.

global optimum solution (Abbass 2000).

In breeding programs, the genetic gain achieved by selective breeding depends on the presence of additive genetic variation in the population. So, the success of a selective breeding program will depend on the genetic variation in the base population, as well as how this variation is maintained from one generation to the next (Puttaraksar 2004). So, for nuclei of breeding programs it is desired to optimize the genetic progress, controlling coancestry/inbreeding and maintaining genetic variability. In this case, the optimization of functions like OF6 $\left(\mathrm{w}_{4}=\mathrm{w}_{5}=\mathrm{w}_{6}=0.01\right)$ seems to be a good alternative for the studied Nile tilapia and coho salmon populations.

When uniformity is desired in the commercial level, a common practice used by fish farmers to reduce the variability is grading the animals several times during the grow-out phase, which is harmful to fish welfare, increases the mortality rate due to stress after manipulation and increases the labor costs (Garcia et al. 2013; King et al. 2006). An alternative proposed in this study is to improve uniformity by using mate selection under appropriate OFs. Our results evidenced that if the purpose is to use the fishes as multipliers in the commercial level, a good alternative seems to be performing mate selection using a OF similar to OF5, which reduced the expected genetic variability of the progeny without compromising genetic gain and coancestry/inbreeding. It should be noted that, for all mating strategies, the phenotypic variability of the future progeny would also depend on the variance of non-additive effects, environmental effects and the variance related to Mendelian segregation, responsible for half of the additive genetic variance (Falconer and Mackay 1996).

In a previous study (Yoshida et al. 2017), we showed that the mate selection algorithm was computationally efficient and flexible for practical applications in aquaculture breeding when the expected merit of the future progeny, the coancestry and the inbreeding were used as components to be considered in the optimization of the objective function. Mate selection showed to be efficient in maximizing genetic progress while controlling coancestry and inbreeding for both Nile tilapia and coho salmon populations (Yoshida et al. 2017). In the current study, we accounted for components related to genetic variability in the optimization of the OF and the results showed that the genetic variability of the progeny can be shaped, depending on the objective to use the animals, without compromising the other components of the OF. It would be interesting to perform a simulation study to investigate the consequences in the long-term inbreeding and genetic progress by applying mate selection accounting for genetic variability.

\section{Conclusion}

The mate selection algorithm accounting for genetic variability was effective in directing the mattings to produce animals with higher or lower expected genetic variability, depending on the purpose of the use of the animals and, at the same time, in optimizing the genetic progress under controlled inbreeding.

\section{Acknowledgments}

The authors are grateful to PeixeGen research group in Brazil and Aquainnovo in Chile for providing the Nile tilapia and coho salmon dataset, respectively. GMY acknowledge Fundação do Amparo à Pesquisa do Estado de São Paulo (FAPESP, process number 2014/ 20626-4 and 2015/25232-7) for doctoral fellowship and RC acknowledge Conselho Nacional de Desenvolvimento Científico e Tecnológico (CNPq, process number 308636/2014-7) for fellowship.

\section{References}

Abbass, H., 2000. Computational Intelligence Techniques for Decision Making with Applications to the Dairy Industry. Queensland University of Technology.

Baras, E., Jobling, M., 2002. Dynamics of intracohort cannibalism in cultured fish. Aquac. Res. 33, 461-479. http://dx.doi.org/10.1046/j.1365-2109.2002.00732.x.

Beardmore, J.., Mair, G.., Lewis, R.., 2001. Monosex male production in finfish as exemplified by tilapia: applications, problems, and prospects. Aquaculture 197, 283-301. http://dx.doi.org/10.1016/S0044-8486(01)00590-7.

Carvalheiro, R., Kinghorn, B., de Queiroz, S.A., 2010a. Mate selection accounting for connectedness. Proceedings of the 9th World Congress on Genetics Applied to Livestock Production 1-6.

Carvalheiro, R., de Queiroz, S.A., Kinghorn, B., 2010b. Optimum contribution selection using differential evolution. Rev. Bras. Zootec. 39, 1429-1436. http://dx.doi.org/10. 1590/S1516-35982010000700005.

Dufflocq, P., Lhorente, J.P., Bangera, R., Neira, R., Newman, S., Yáñez, J.M., 2016. Correlated response of flesh color to selection for harvest weight in coho salmon (Oncorhynchus kisutch). Aquaculture 6-11. http://dx.doi.org/10.1016/j.aquaculture. 2016.08.037.

Falconer, D.S., MacKay, T.F.C., 1996. Introduction to Quantitative Genetics. Pearson, Prentice Hall editions, Harlow, UK.

Garcia, F., Romera, D.M., Gozi, K.S., Onaka, E.M., Fonseca, F.S., Schalch, S.H.C., Candeira, P.G., Guerra, L.O.M., Carmo, F.J., Carneiro, D.J., Martins, M.I.E.G., Portella, M.C., 2013. Stocking density of Nile tilapia in cages placed in a hydroelectric reservoir. Aquaculture 410-411, 51-56. http://dx.doi.org/10.1016/j.aquaculture. 2013.06.010.

Gilmour, K.M., Dibattista, J.D., Thomas, J.B., 2005. Physiological causes and consequences of social status in salmonid fish. Integr. Comp. Biol. 45, 263-273. http:// dx.doi.org/10.1093/icb/45.2.263.

Gjedrem, T., 2005. Selection and Breeding Programs in Aquaculture. Springer-Verlag, Berlin/Heidelberg. http://dx.doi.org/10.1007/1-4020-3342-7.

Gondro, C., Kinghorn, B., 2008. Application of Evolutionary Algorithms to Solve Complex Problems in Quantitative Genetics and Bioinformatics. (Guelph).

Hohenboken, W.D., 1985. The manipulation of variation in quantitative traits: a review of possible genetic strategies. J. Anim. Sci. 60, 101. http://dx.doi.org/10.2527/jas1985. 601101x.

Jakobsen, P.J., Johnsen, G.H., Holm, J.C., 1987. Increased growth rate in Atlantic salmon parr (Salmo salar) by using a two-coloured diet. Can. J. Fish. Aquat. Sci. 44, 1079-1082. http://dx.doi.org/10.1139/f87-128.

Janhunen, M., Kause, A., Järvisalo, O., 2012a. Costs of being extreme - do body size deviations from population or sire means decrease vitality in rainbow trout? Aquaculture 370-371, 123-129. http://dx.doi.org/10.1016/j.aquaculture.2012.10. 013.

Janhunen, M., Kause, A., Vehviläinen, H., Järvisalo, O., Salgado, C., Damsgård, B., Bijma, P., Olesen, I., 2012b. Genetics of microenvironmental sensitivity of body weight in rainbow trout (Oncorhynchus mykiss) selected for improved growth. PLoS One 7, e38766. http://dx.doi.org/10.1371/journal.pone.0038766.

Kause, A., Janhunen, M., Vehviläinen, H., Koskinen, H., Nousiainen, A., 2014. Improving Uniformity of Growth by Mating and Selection Strategies in Rainbow Trout. In: Proceedings, 10th World Congress of Genetics Applied to Livestock Production, pp. 1-4.

Khaw, H.L., Ponzoni, R.W., Yee, H.Y., Aziz, M.A. bin, Mulder, H.A., Marjanovic, J., Bijma, P., 2016. Genetic variance for uniformity of harvest weight in Nile tilapia 
(Oreochromis niloticus). Aquaculture 451, 113-120. http://dx.doi.org/10.1016/j. aquaculture.2015.09.003.

King, W., Buckley, L.J., Berlinsky, D.L., 2006. Effect of acclimation temperature on the acute stress response in juvenile Atlantic cod, Gadus morhua L., and haddock, Melanogrammus aeglefinus L. Aquac. Res. 37, 1685-1693. http://dx.doi.org/10.1111/ j.1365-2109.2006.01623.x.

Kinghorn, B.P., 2011. An algorithm for efficient constrained mate selection. Genet. Sel. Evol. 43 (1).

Marjanovic, J., Mulder, H.A., Khaw, H.L., Bijma, P., 2016. Genetic parameters for uniformity of harvest weight and body size traits in the GIFT strain of Nile tilapia. Genet. Sel. Evol. 48, 41. http://dx.doi.org/10.1186/s12711-016-0218-9.

Meuwissen, T.H.E., 1997. Maximizing the response of selection with a predefined rate of inbreeding. J. Anim. Sci. 75, 934-940.

Moreno, A., Ibáñez-Escriche, N., García-Ballesteros, S., Salgado, C., Nieto, B., Gutiérrez J.P., 2012. Correlated genetic trend in the environmental variability of weight traits in mice. Livest. Sci. 148, 189-195. http://dx.doi.org/10.1016/j.livsci.2012.05.009.

Oliveira, C.A.L., Ribeiro, R.P., Yoshida, G.M., Kunita, N.M., Rizzato, G.S., de Oliveira, S.N., dos Santos, A.I., Nguyen, N.H., 2016. Correlated changes in body shape after five generations of selection to improve growth rate in a breeding program for Nile tilapia Oreochromis niloticus in Brazil. J. Appl. Genet. 57, 487-493. http://dx.doi. org/10.1007/s13353-016-0338-5.

Omasaki, S.K., Janssen, K., Besson, M., Komen, H., 2017. Economic values of growth rate, feed intake, feed conversion ratio, mortality and uniformity for Nile tilapia. Aquaculture. http://dx.doi.org/10.1016/j.aquaculture.2017.04.013.

Piyasatian, B.N., Kinghorn, B.P., 2003. Balancing genetic diversity, genetic merit and population viability in conservation programmes. J. Anim. Sci. 120, 137-149.

Puttaraksar, N., 2004. GIFT Technology Manual: An Aid to Tilapia Selective Breeding. (Malaysia).

Sae-Lim, P., Komen, H., Kause, A., van Arendonk, J.A.M., Barfoot, A.J., Martin, K.E., Parsons, J.E., 2012. Defining desired genetic gains for rainbow trout breeding objective using analytic hierarchy process. J. Anim. Sci. 90, 1766-1776. http://dx.doi. org/10.2527/jas.2011-4267.

Sae-Lim, P., Kause, A., Janhunen, M., Vehviläinen, H., Koskinen, H., Gjerde, B., Lillehammer, M., Mulder, H.A., 2015. Genetic (co)variance of rainbow trout (Oncorhynchus mykiss) body weight and its uniformity across production environments. Genet. Sel. Evol. 47, 46. http://dx.doi.org/10.1186/s12711-015-0122-8.
Sae-Lim, P., Kause, A., Lillehammer, M., Mulder, H.A., 2017. Estimation of breeding values for uniformity of growth in Atlantic salmon (Salmo salar) using pedigree relationships or single-step genomic evaluation. Genet. Sel. Evol. 49, 33. http://dx.doi. org/10.1186/s12711-017-0308-3.

Shepherd, R., Kinghorn, B., 1998. A Tactical Approach to the Design of Crossbreeding Programs. In: Proceedings of the Sixth World Congress on Genetics Applied to Livestock Production, pp. 431-438 (Armidale).

Shepherd, R., Kinghorn, B., 1999. Algorithms for mate selection. Proc. Assoc. Advmt. Anim. Breed. Genet. 13, 126-129.

Sonesson, A.K., Meuwissen, T.H.E., 2000. Mating schemes for optimum contribution selection with constrained rates of inbreeding. Genet. Sel. Evol. 32, 231.

Woolliams, J.A., Thompson, R., 1994. A Theory of Genetic Contributions. In: Proceedings of the 5th World Congress on Genetics Applied to Livestock Production. Vol. 19. pp. $127-134$.

Woolliams, J.A., Berg, P., Dagnachew, B.S., Meuwissen, T.H.E., 2015. Genetic contributions and their optimization. J. Anim. Breed. Genet. 132 (2), 89-99.

Yáñez, J.M., Bassini, L.N., Filp, M., Lhorente, J.P., Ponzoni, R.W., Neira, R., 2014. Inbreeding and effective population size in a coho salmon (Oncorhynchus kisutch) breeding nucleus in Chile. Aquaculture 420 (421), S15-S19. http://dx.doi.org/10. 1016/j.aquaculture.2013.05.028.

Yañez, J.M., Bangera, R., Lhorente, J.P., Barria, A., Oyarzun, M., Neira, R., Newman, S., 2016. Negative genetic correlation between resistance against Piscirickettsia salmonis and harvest weight in coho salmon (Oncorhynchus kisutch). Aquaculture 459, 8-13. http://dx.doi.org/10.1016/j.aquaculture.2016.03.020.

Yoshida, G.M., Yáñez, J.M., de Queiroz, S.A., Carvalheiro, R., Lhorente, J.P., 2016. Comparison between optimum contribution and mate selection in coho salmon breeding. Int. Meet. Adv. Anim. Sci. 1 (2016), 45182.

Yoshida, G.M., Yáñez, J.M., de Oliveira, C.A.L., Ribeiro, R.P., Lhorente, J.P., de Queiroz, S.A., Carvalheiro, R., 2017. Mate selection in aquaculture breeding using differential evolution algorithm. Aquac. Res. http://dx.doi.org/10.1111/are.13365.

Yoshida, G.M., Yáñez, J.M., de Queiroz, S.A., Carvalheiro, R., 2018. Comparison between Optimum Contribution and Mate Selection in Aquaculture Breeding Using Simulated Data. In: Proceedings of the 11th World Congress on Genetics Applied to Livestock Production, pp. 1-4 (Auckland). 